\title{
Electronic Commerce Technology Adoption at the Scientific and Industrial Research and Development Centre
}

\author{
Cosmas Rashama $^{{ }^{*}}$, Wilson Mungwena ${ }^{2}$, Tonderai Damba ${ }^{1}$ \\ ${ }^{1}$ Department of Electrical Engineering, University of Zimbabwe, Harare, Zimbabwe \\ ${ }^{2}$ Department of Mechanical Engineering, University of Zimbabwe, Harare, Zimbabwe \\ Email: *cmosrash@yahoo.com
}

Received April 30, 2013; revised May 31, 2013; accepted June 10, 2013

Copyright (C) 2013 Cosmas Rashama et al. This is an open access article distributed under the Creative Commons Attribution License, which permits unrestricted use, distribution, and reproduction in any medium, provided the original work is properly cited.

\begin{abstract}
This paper focuses on the level of adoption of E-Commerce Technology at the Scientific and Industrial Research and Development Centre (SIRDC), a Zimbabwean organization established by an act of parliament, with a mandate to develop, adopt and adapt new technologies for the benefit of Zimbabwean companies and organizations. The study was done in 2004 and the findings reviewed in 2012 with similar results. The objective of the study was to establish whether E-commerce technology adoption would result in the organization being more efficient and effective in delivering its mandate and then establish the level of adoption of the technology at the centre using abstraction and a questionnaire survey. Abstraction results showed that organizations which had fully embraced the technology were more efficient and effective while the survey revealed that the centre had partially adopted the technology. It was recommended that the centre should fully embrace the technology and market it to other organizations as per its mandate.
\end{abstract}

Keywords: Electronic Commerce; Non-Repudiation; Internet; Intranet; Extranet

\section{Introduction}

The Scientific and Industrial Research and Development Centre (SIRDC), Zimbabwe's Technology Centre, presents a fascinating case study due to the fact that it was established by government in 1994 with a mandate to develop, adopt and adapt new technologies that will improve the competitiveness of the Zimbabwean industries and institutions globally. Since the use of Electronic Commerce (E-Commerce) technology has resulted in industrialised countries realising great benefits nationally and globally, its adoption, adaption to the local environment and subsequent usage by the Scientific and Industrial Research and Development Centre will enhance the competitiveness of the centre in delivering its mandate. The study undertook to establish whether the centre was taking a leadership role in the adoption of E-Commerce Technology in the country as required by its mandate.

\section{Objectives}

In order for the study to establish whether the Scientific

${ }^{*}$ Corresponding author. and Industrial Research and Development Centre was effectively and efficiently delivering its mandate, through the adoption and usage of E-Commerce Technology, the following three questions had to be answered:

- Does the adoption and usage of E-Commerce Technology result in the centre efficiently and effectively delivering its mandate?

- To what extent has the Scientific and Industrial Research and Development Centre taken a leading role in adopting E-Commerce Technology for the sake of improving its effectiveness and efficiency in delivering its mandate?

- To what extent has the centre marketed E-Commerce Technology to industry and other organizations?

\section{Theory and Literature Review}

E-Commerce is a modern business practice associated with the buying and selling of information, products, and services via Internet [1]. The Internet has become the fastest growing electronic technology in world history. In the United States, for example, after electricity became publicly available, 46 years passed before 30 percent of 
American homes were wired; 38 years passed before the telephone reached 30 percent of US households, and 17 years for television [2]. The Internet required only seven years reaching 30 percent of American households. E-Commerce is an integral market, with no geographical boundaries that includes all the necessary operations to carry out a transaction [3]. The rapid proliferation of Internet and the world-wide web has created a fast growing electronic channel for marketing.

E-Commerce Technology has transformed business operations into real-time transactions, conducted globally, with heightened accuracy and reduced waste. It is the technology that is driving globalisation. E-Commerce Technology has been in existence for the past 50 years and its adoption has been mainly measured by the amount of transactions that have been done using the technology and predictions of future transactions from available data. Although it is difficult to gauge the reliability of such predictions, most researchers are agreed that transactions conducted using the E-Commerce Technology surpassed US\$ 6.9 trillion by the year 2005 $[4,5]$. Although they are founded and unfounded fears associated with the use of the technology, organisations using the technology are satisfied by the results so far.

E-Commerce is commerce for the era of globalization, an era in which networks, and in particular the Internet, make it possible to create and manage an electronic market operated through computers and at a distance, dealing in a full range of products, services, technologies and goods. It is an integral market [3], with no geographical boundaries that includes all the necessary operations to carry out a transaction. It also features the identification and selection of potential partners, assisted trade negotiations, trade reference data, access to information on support services, banks and banking transactions, attention to specific needs for special clients, handling of all the necessary documentation safely and with complete confidentiality.

E-Commerce offers multiple benefits to suppliers, clients and consumers. Public and private companies and organizations have seen enough benefits [6] with the generation of new opportunities for business, direct access to distant markets offering global presence, personalized services resulting in massive personalisation, improved competition resulting in increased competitiveness, substantial reduction in costs and time involved, shorter delivery chain, fast technology transfer, better organisational learning opportunities, relatively small investments to penetrable large markets and up to date information. Some of the benefits to consumers include global selection with purchases done from anywhere, quality of service, personalized products and services, quick response to needs, reduction in prices, new products and services.
Two models are widely used today for the development of an E-Commerce infrastructure. The first is the Information-Communication-Distribution-Transaction (ICDT) model that was first proposed by Abert Angehrn $[7,8]$. It takes its name from the four virtual spaces created by the Internet: Virtual information space (VIS), Virtual communication space (VCS), Virtual distribution space (VDS) and Virtual transaction space (VTS). The four spaces are treated separately because they correspond to different strategic objectives and require different types of investment and organisational adjustments. Clarke provided a five-phase model of E-Commerce that included the following stages [9]: the pre-contractual phase, the contractual phase, the ordering and logistic phase, the settlement phase and the post-processing phase. The five-phase model is basically the same as the ICDT model. The two only differ in that the ICDT model does not offer post-processing functions.

\section{Methods}

This was a case study research of the Scientific and Industrial Research and Development Center through a questionnaire and direct observation. The study focused on the activities of the centre to establish whether the centre was using E-Commerce Technology in the conduct of their business for the purpose of improving efficiency and effectiveness. A case study was more appropriate because it enabled a thorough investigation of the variables. However it was difficult to generalize the findings of the case study because the observations could have been situational.

The Scientific and Industrial Research and Development Centre had a staff complement of 150 employees. Due to limitations of cost, time and the need to maintain high accuracy questionnaires were distributed to 120 of the 150 staff members. In order to ensure that the results were authentic, the chosen employees included all managers, all scientists, all technicians and all secretaries because they were the ones that were supposed to use E-Commerce in their day-to-day operations. The selection of subjects who were supposed to use E-Commerce in their day-to-day operations eliminated the major weakness of judgmental sampling. This judgmental sample was also chosen because the researcher was familiar with the organization. Employees outside these categories were randomly selected so that the required number of 120 was realised. The use of judgmental sampling, which is a non-probability sampling method, had some effect on the validity of the results because the error could not be quantified.

It is important to note that some of the employees who were given questionnaires chose not to cooperate during the survey thereby causing some distortions to the established results. It is generally the practice that $5 \%-15 \%$ 
of the targeted participants would actually cooperate by completing the research instrument honestly and returning the instrument back in any self-administered questionnaire. It was therefore expected that at least 18 questionnaires would be returned back by the targeted participants. For this research, 86 questionnaires were returned because the questionnaires were numbered and a register for distributed questionnaires kept a situation that enabled easy follow ups. Researcher also sought the support of senior management before the study was done which also helped to increase the response rate. The register was kept without the respondents' knowledge in order to preserve a sense of confidentiality.

In conducting the survey, questionnaires and personal observations were used as research instruments. A questionnaire was designed as the main research instrument in order to solicit responses from the subjects that would enable one to answer with a high degree of accuracy the research problem. In order to ensure that the questionnaire was simple and straight forward, the majority of the questions used had single choice answers. This also served to minimise ambiguity in the questions as well as the responses. The major advantages of questionnaire that justified its use in this study included the fact that it could be implemented at low cost, it was not subjected to interviewer bias, it was good for quantifying responses and it was more convenient for respondents. The major disadvantages of the questionnaire that the study had to take into account was that it was slow to implement thereby justifying the need to number questionnaires and keeping a register for the purpose of following up respondents. A cutoff date and minimum number required was also established by the researcher to ensure that once the date was due and enough questionnaires were available, the study could proceed without worrying about the questionnaires that were not returned.

In order to ensure quality responses, draft questionnaires were sent to selected staff members with doctorate degrees in social sciences for them to check and comment on the quality of questions. The questionnaire was then pilot tested on selected subjects to determine if the instrument collected the type of information it was intended to collect. Open-ended questions were harder to implement thereby justifying keeping them to an absolutely necessary minimum in the study. There was potential for non-response bias, which justified the use of short and simple questions that were not sensitive.

The questionnaire started by looking at whether the centre had the E-Commerce tools and then further focused on whether these tools were widely distributed within the centre or whether they were found in a few critical areas, in which case the questionnaire then established whether there was an established widely shared policy over the distribution of the E-Commerce tools within the organization. Having established how the organization was equipped to use E-Commerce as a business tool, the questionnaire then focused on the usage of the tools for the intended purpose.

In terms of usage, the questionnaire mainly focused on how the centre used the four virtual spaces that were available to all E-Commerce users. The questionnaire explored usage of the virtual information space. The main area of concern in this regard was how the centre used E-Commerce Technology for internal and external information sharing. While exploring the usage of the virtual information space, the questionnaire also established whether the centre had databases for all its functional areas and whether these databases were widely accessible to internal and external stakeholders.

The questionnaire then focused on the usage of the virtual communication space. It looked at how widely the centre used the virtual communication space for internal and external communication. The major issues of concern were the effective and efficient use of E-mail and the effective and efficient use of chat. The questionnaire also focused on how effectively the centre used the virtual transaction space for internal and external transactions. The questionnaire established whether the centre used the virtual transaction space to sell their products and services to their customers through the exchange of orders and invoices. The questionnaire also established whether the centre used the virtual transaction space for payment processing.

Having looked at transaction processing, the questionnaire established whether the centre had products and services that could be digitised. If the products and services could be digitised, then it was investigated whether the centre was using the virtual distribution space for distributing the products. Having distributed the products and services, the study established whether the centre offered after sales support services using the four virtual spaces.

How the centre was marketing E-Commerce Technology to industry, government and institutions that could benefit from the technology in the country was also an issue of concern in the questionnaire. The questionnaire looked at whether the centre had a marketing program for the technology, in which case the study then established whether the centre was succeeding in marketing the technology.

Researcher's organization was housed at the Scientific and Industrial Research and Development Centre. This enabled direct personal observations to be done about the efficiency and effectiveness of the centre through the adoption and usage of E-Commerce Technology at the centre. Direct personal observation was used as a research instrument because it enabled the subjects to behave naturally without being aware that they were being 
observed. However, researcher did not have an opportunity to probe for reasons or to investigate further.

Direct observations were done about how the centre generated, shared and stored information within and without the organization. The researcher also looked at how the centre's employees communicated within and without the organization. Observations were also done on how the centre conducted transactions when purchasing and selling products and services. Observation method was used to establish whether E-Commerce Technology could enable the centre to be more efficient and effective in delivering its mandate.

Percentages and tables were used in the analysis of the data because the subjects returned only $71 \%$ of the questionnaires send out. The results first focused on establishing whether the center had the required tools to participate in E-Commerce. Data was also presented on the usage of the virtual communication space, the virtual information space, the virtual transaction space, the virtual distribution space, fears and concerns at the centre about using the internet for business and internet marketing usage. The results were presented in the order given above.

\section{Results}

The study revealed that $89 \%$ of the respondents had access to the internet, $8 \%$ did not have access to the internet while $3 \%$ did not respond to the question. Of the $89 \%$ with internet access, 56\% had internet tools in their offices while $44 \%$ did not have any internet tools in their offices. Of the $44 \%$ that did not have Internet tools in their offices, $70 \%$ used the internet room that was specifically put in place by management to facilitate internet access. $12 \%$ used Internet cafes while the University of Zimbabwe, Institutes' computer labs and the directors' offices were used by $6 \%$ each. Direct observation through corporate literature revealed that the center's management had resolved that all offices within the center should have internet connection points installed just like the power points and telephone points put during construction in most office blocks. It was believed by installing internet points in every office, all members of staff would have access to the internet tools. However due to limit resources, some offices did not have the internet points nor the computers required for internet connection at the time of the study. The survey however revealed that $75 \%$ of the respondents did not have any knowledge about the policy that governed the distribution of internet tools within the organization. $20 \%$, who could have been managers new the policy while $5 \%$ did not give a response.

All the secretaries had internet tools in their offices while 4 middle and senior managers who had donor funded projects had the internet tools in their offices. Ten scientists' offices out of the observed twenty, the accounts office and the data processing office had computers connected to the internet. The sales office and the purchasing office had computers but they were not connected to the internet. The centre had an institute called the informatics and electronics institute. In addition to carrying out research and development activities, the institute administered the centre's local area network. The local area network server was connected to Zanet, the service provider, via telephone lines as well as a radio link. The main access method was through the radio link with the telephone lines only being used when the radio link was down.

Direct personal observation revealed that for internal communication, the centre used notice boards for passing information. There were seven three-storey buildings that were operational within the centre and each of the buildings had nine corridors. Each corridor had a notice board where messages were posted. For every message that was communicated to staff, either by printing one copy and photocopying the rest or by printing all, more than sixty four copies were generated that include sixty three for the notice boards, one for the office copy and copies to senior management depending on who the message was copied to.

Internal communication also involved the use of telephone extensions as well as face-to-face direct communication to communicate urgent and important messages. Direct observation also revealed that communication with the outside world involved the use of telephones even if the other party had an E-mail address. Letters were also used for communication and most managers instructed that the letters be hand delivered by the centre's drivers if the recipients were around Harare. For recipients outside Harare, the letters were posted.

The managers who had internet tools in their offices had their E-mails opened by the secretaries who then printed them before they could read them. The managers then wrote responses where there was need to respond on papers for their secretaries to send them on their behalf. The secretary then printed the response and filed the original mail as well as the response in a physical file.

The survey revealed that $80 \%$ of the respondents had electronic mail addresses set up for them by the center, $4 \%$ did not have electronic mail addresses set up for them by the center while $8 \%$ did not respond to the question. $81 \%$ of the respondents had their own personal private E-mail addresses $10 \%$ did not have while $9 \%$ did not respond to the question. $47 \%$ of the respondents received and sent up to $5 \mathrm{E}$-mails per week, while $33 \%$ of the respondents received or sent 5 - $10 \mathrm{E}$-mails per week. $15 \%$ sent and receive 10 - 15 E-mails per week with 5\% not responding to the question. Those who did not respond to the question were assumed to receive less than 5 
E-mails per week.

Observations revealed that the centre had a web site where most of the centre's activities were published. The majority of the respondents, 70\%, have their department's products and services on the SIRDC website while only $27 \%$ of the respondents did not have their products and services on the SIRDC web site. $3 \%$ of the respondents did not respond to the question. A visit to the web site, also clearly showed that all the centre's products and services offered to outsiders were listed on the web site. $41 \%$ of the respondents had their departments' information on the SIRDC's web sites updated monthly. This is followed by $20 \%$ of the respondents whose department's information is updated annually. $13 \%$ of the respondents reported that their department's information on the web site is never updated, while $4 \%$ did not give a response to the question. The survey revealed that $61 \%$ of the respondents' departments offer after sales support services to their customers while $22 \%$ did not. $17 \%$ did not respond to the question. Of the $61 \%$ whose departments offered after sales service to their customers, 50\% used telephones to communicate with the customers while 31\% each use E-mail and personal visits, 6\% use the web site, while $17 \%$ use the post.

On average, $22 \%$ of the respondents stay on the internet for less than 30 minutes. $42 \%$ stay on the internet for between 30 - 60 minutes while $28 \%$ stay on the internet for 60 - 90 minutes per day. 36\% of the respondents stay on the internet for more than one hour per day. Those that did not respond to the question were assumed to stay on the internet for less than 30 minutes per day.

The survey results revealed that $22 \%$ of the respondents reported that their departments had databases on the SIRDC local area network, while $65 \%$ of the respondents' department did not have any database on the local area network. $12 \%$ of the respondents did not respond to the question. Of the respondents who reported that their departments had databases on the SIRDC local area network, $16 \%$ reported that these databases were on the SIRDC web site, $70 \%$ reported that the databases were not available on the web site while $14 \%$ did not respond to the question. A visit to the web site revealed that only the finance department had a database that was on the local area network.

75\% reported that they could access general information from the SIRDC web site. This was followed by $28 \%$ of the respondents who reported that they could access the SIRDC calendar from the web site. Although $14 \%, 11 \%$ and $17 \%$ of the respondents reported that they could access rules and regulations, in-house training materials and minutes of meetings respectively, a visit to the web site revealed that these were not available on the web site at all. What can be accessed on the web site is the SIRDC calendar that shows the coming events in- cluding seminars as well as the general information. There were no seminar presentations at all.

Abstraction results revealed that the centre had a purchasing department that processes all purchases by the centre as well as a sales office that processes all sales of the centre's products and services. For anything to be purchased by the centre, the requesting department had to look for three quotations and fill in a "Blue Form" that acted as a requisition form and attach the three quotations. The form would then be approved by the director of the department before going for approval of the Financial Controller, Deputy Director General Finance and Administration or the Director General depending on the amount.

Once the requisition had been approved, it would then go to the purchasing department where an order would be prepared. The order would have to be signed by the Financial Controller, Deputy Director General Finance and Administration or the Director General depending on whom of the three approved the requisition. The signed order would then be used by the purchasing department to purchase the required goods or services. In some cases, the order would be given to the requesting department to proceed with the purchase. The order book had three copies, that is, a white copy that would be presented to the supplier, a yellow copy that would be used by the finance department to effect payment and a pink copy that would remain in the order book for records.

Once the goods were delivered, and an invoice was received, the finance department would then effect payment. They would then write a cheque to the supplier and attach the invoice as well as the yellow copy of the order before sending the cheque to two signatories who would then sign the cheque before it is send to the supplier. Similarly, the sales office would also insist on orders for them to supply any goods or services except for cash purchases. They would then issue a receipt and invoice before any goods were delivered.

From the survey results, $15 \%$ of the respondents had their department's products and services on the web site that could be directly ordered by clients. $70 \%$ had no such facility while the other $15 \%$ did not respond to the question. A visit to the SIRDC web site revealed that none of the products offered by SIRDC could be ordered directly from the web site. $66 \%$ of the respondents had never ordered products or services on the internet, $23 \%$ ordered while $11 \%$ did not respond to the question. The average order frequency of the $23 \%$ that had ordered products and services from the internet was once in every 6 months.

Of the $23 \%$ that had ordered products or services on the internet, $30 \%$ of them used the internet to pay for the products or services ordered at an average frequency of once per year, while 56\% did not use the internet for 
paying. $14 \%$ did not respond to the question. The low usage of the internet transaction space was as a result of deep-rooted fears in the respondents with $44 \%$ having a level of confidence below $10 \%$ with the information received or send during the ordering and payment process. $42 \%$ had a confidence level between $10 \%$ - 20\%, $14 \%$ were above $20 \%$. The few that had used the internet for ordering products and services did so about once in every 6 months and a further small percentage of these paid for the order using the internet. Although $15 \%$ of the respondents revealed that their departments' products and services could be ordered directly from the web site and visits to the web site revealed that no products could be ordered from the site. Since none of the products could be ordered directly from the web site, it therefore follows that the center cannot send, receive and confirm orders using the web site. Abstraction results revealed that the centre had the required software to enable transaction and distribution processing.

Abstraction results revealed that the centre had not established any distribution channels for its products and services. All those purchasing the centre's products or services had to physically visit the centre which is located 25 kilometers from the Harare city centre. The survey results revealed that $52 \%$ of the respondents' department products and services could be digitised, $41 \%$ could not be digitized while $7 \%$ did not respond to the question. Of the $52 \%$ of the respondents whose departments had products and services that could be digitised, $31 \%$ of them used the internet for their distribution; $56 \%$ did not use the internet for their distribution while $11 \%$ did not respond to the question.

It is important to note that $85 \%$ of the respondents believe that the centre had not marketed Electronic Commerce Technology to the Zimbabwean government, industry and organizations. $10 \%$ believed the center had marketed the technology while 5\% did not respond to the question. Abstraction results show that the centre could be more efficient and effective if it used E-Commerce Technology for marketing its products and services through one-to-one marketing that was less costly and timely. The survey results show that the centre was using costly methods for marketing as revealed on Table 1. This could be due to the fact that traffic to the site is very low thereby not attracting advertisers.

The survey results showed that most of the computers at the centre were protected from viruses. Those who indicated that their computers were not protected from viruses could have had stand alone systems that were not threatened by virus attacks, since all the computers on the local area network were protected from viruses. The major concerns about using the internet for business seen on Table 2 are to do with security, privacy and confidentiality.
Table 1. Table showing how the respondents market their department's products and services to potential customers (Multiple response questions).

\begin{tabular}{lc}
\hline Method & Percentage \\
\hline E-mail & 19.35 \\
Internet Banners & 0.00 \\
SIRDC web site & 14.52 \\
Mail shots & 0.00 \\
Telephone & 27.42 \\
Print media & 12.90 \\
Electronic media & 1.61 \\
Other & 9.68 \\
Not involved in marketing & 14.52 \\
\hline
\end{tabular}

Table 2. Table showing respondents' concerns and fears about using the internet for business (Multiple response question).

\begin{tabular}{lc}
\hline Concerns and Fears & Percentage \\
\hline Security & 42.31 \\
Privacy \& Confidentiality & 19.23 \\
Server faults & 11.54 \\
No fears and concerns & 11.54 \\
Hackers & 7.69 \\
Lack of personal touch & 3.85 \\
Spam & 3.85 \\
Transaction errors & 3.85 \\
Piracy (Protection of intellectual property) & 3.85 \\
Few Zimbabweans with internet access & 3.85 \\
Risk of none payment & 3.85 \\
No security competent personal in the country & 3.85 \\
Speed of information transmission & 3.85 \\
Abuse & 3.85 \\
\hline
\end{tabular}

\section{Discussion}

The result on the availability of internet tools was impressive considering that only $70 \%$ of Americans 2 had internet access then. The results seem to suggest that SIRDC had the required capacity and tools to adopt Electronic Commerce as a business tool for the purpose of improving efficiency and effectiveness. The availability of a local area network, as well as a wide area network through the link to Zanet, coupled with management's desire to see internet tools in every office, was a clear indication of management's commitment to the use of internet technology for improving efficiency and effectiveness. The distribution of the internet tools within the organization was however flawed because it ignored key personal such as the purchasing office, the sales office, the scientists and the managers who should effectively utilize these tools for E-Commerce if efficiency and effectiveness was to be achieved. The results also revealed that the established policy on the distribution of 
internet tools was not widely shared a symptom of poor communication.

The use of Physical notice boards for communicating was not efficient and effective because it was more costly than E-mail or electronic notice boards, it took more time to generate and to reach recipient and did not give recipients an opportunity to give feedback. The use of telephones to communicate to outsiders with E-mail addresses was not efficient and effective because for local calls, although costs were almost the same for E-mails and telephones, the time required to communicate was more for telephones compared to using E-mail. For long distance communication, the cost was even more due to the time and the tariffs that were higher. The use of drivers to deliver printed mail to recipients with E-mail addresses was also costly and time consuming considering the cost of printing, paper, fuel and personal. E-mail is paperless and instantaneous. Posted letters were even worse in terms of time and costs.

Worldwide, the use of email is replacing traditional forms of communication such as telephones and postal services. The usage is also growing at a fast pace compared to other technologies that have been developed. The reason for this growth is the efficiency and effectiveness of the technology. It was therefore important that the centre use E-mail in order for the centre to be more efficient and effective in delivering its mandate. The fact that more than $80 \%$ of the respondents had both corporate and private E-mail addresses implies that most of the SIRDC staff members could use electronic mail for communication purposes. The usage of E-mail at the centre however was very low as evidenced by the number of E-mails that were send or received by the respondents. For effective usage of E-mail, it was expected that the majority of the respondents were supposed to send and receive more than 50 E-mails per week. The results showed that the facility was underutilized at the centre contrary to the theory that this was the most widely used service of the internet $[2,11]$.

The daily usage of the internet per employee was between 30 - 60 minutes on average. Considering the functions on the internet, this was very low. This could be due to the fact that the employees were more comfortable using physical tools rather than the virtual information space for business. The results on how often the web site was updated, suggest that the centre's web site was updated regularly. However, the frequency of update was not consistent in the various departments. Although the centre offered after sales support services to customers, it was underutilizing the available internet tools for that function. If the centre would efficiently and effectively use the web, they would also achieve efficiency and effectiveness through the reduction in the costs of information sharing as well as the time required to share the in- formation [2].

The results suggest that the centre does not have an integrated internet/intranet/extranet system nor does it have databases a key component of intranet and extranet systems. Apart from the general information that could be accessed on the intranet, the rest of the information and communication functions of the intranet and extranet are underutilized at the centre. This could be due to lack of knowledge at the centre about the effective and efficient use of the intranet and extranets. Intranets and extranets could be important tools if implemented as an integrated system. An integrated internet/intranet/extranet solution could be the best investment the centre could make to face today's globalised world [12,13].

The center was not utilizing the virtual transaction space for transaction processing. The main reason why the centre's staff did not use the internet for transaction processing could have been due to deep rooted security, privacy and confidentiality fears. This is in line with theory [13] because despite the fact that security systems are being improved regularly and internet systems are more secure than the traditional physical systems, people are still afraid to use the internet for transaction purposes. Results seem to suggest that the centre's staff were not following closely on the security and privacy technologies that were on the internet despite the education levels of the centre's employees. The whole transaction processing system could be automated if they used the virtual transaction space a situation that could result in cost and time savings [2,14]. From a strategic point of view, E-Commerce transactions are a key element for the participation of the centre in the great trade flows and in the profound changes that have taken place in the world of research, business, investment and commerce. It is the main entrance to the real Information Society.

These survey results showed that although the centre had products and services that could be distributed over the internet, the utilization of the internet tools for distribution of products and services at the centre was very low. The abstraction results reveal that the centre is using physical means for the distribution of all their products and services with no distribution channels in place. The centre could be more efficient and effective in the distribution process if they used the virtual distribution space for distributing those products that could be digitised like software and training as well as establish formal distribution channels for those products that cannot be digitised. Further, the marketing of the centre's products and services is heavily reliant on the traditional media as well as traditional methods of mass marketing, ignoring the cheaper tools available.

\section{Conclusions and Recommendations}

From the results of the study, the following conclusions 
about the adoption of Electronic Commerce Technology at the centre can be drawn:

- The full adoption and usage of E-Commerce Technology can result in the centre being more efficient and effective in delivering its mandate as shown in the literature review.

- The centre had partially adopted Electronic Commerce Technology.

- The centre had not marketed E-Commerce Technology to industry and other organizations.

- In light of the above conclusions, it is recommended that:

- The centre implements an integrated internet/intranet/ extranet system that would result in total adoption of Electronic Commerce Technology for the benefit of improving efficiency and effectiveness in delivering its mandate.

- Once the centre fully adopts the technology, it should market the technology to government, industry and organizations in the country in line with its mandate.

It will be important for an investigation to be done to establish the requirements, in terms of human and material resources, for fully adopting E-Commerce Technology since this could be the major hindrance.

\section{Acknowledgements}

The author would like to thank the management of SIRDC for their support during the conduct of this research and all the staff of the centre who participated in the research.

\section{REFERENCES}

[1] T. Liang and J. Huang, “A Framework for Applying Intelligent Agents to Support Electronic Trading,” 2000. http://www.ecrc.nsysu.edu.tw/liang/paper/IAFramework( DSS28,4,2000).pdf

[2] J. I. Cole, "The UCLA Internet Report-Surveying the Digital Future,” 2002. http://www.digitalcenter.org/pdf/InternetReportYearThre e.pdf

[3] R. Lee, "Electronic Commerce: The Quest for a Global, Secure Infrastructure,” Novell Developer Information,
1997.

http://support.novell.com/techcenter/articles/ana19971004 .html

[4] W. H. DeLone and E. R. McLean, "Measuring e-Commerce Success: Applying the DeLone \& McLean Information Systems Success Model," International Journal of Electronic Commerce, Vol. 9, No. 1, 2004, pp. 31-47.

[5] A. Ca`Zorzi, "Electronic Commerce and Development Implications for IDB Action," 2000. http://idbdocs.iadb.org/wsdocs/getdocument.aspx?docnu $\mathrm{m}=1484412$

[6] A. Petri and O. Nixu, "Models of Electronic Commerce," 1995.

http://www.tml.tkk.fi/Opinnot/Tik-110.501/1995/commer ce.html

[7] A. Angehrn, "Designing Mature Internet Business Strategies: The ICDT Model,” European Management Journal, Vol. 15, No. 4, 1997, pp. 361-369. http://www.calt.insead.edu/eis/icdt\%20documents/icdt-e mj-1.pdf

[8] A. Angehrn, "The Strategic Implications of the Internet," The European Institute of Business Administration. http://www.calt.insead.edu/Publication/ICDT/strategicIm plication.htm

[9] R. Clarke, "EDI Is but One Element of Electronic Commerce,” 6th International EDI Conference, Bled, 1993. http://www.rogerclarke.com/EC/Bled93.html

[10] T. Warner, “Applied Business Statistics,” 4th Edition, Juta \& Co. LTD., Cape Town, 1993, pp. 168-173.

[11] D. G. Venolia, L. Dabbish, J. J. Cadiz and A. Gupta, "Supporting Email Workflow,” 2001.

http://www.research.microsoft.com/pubs/69881/tr-2001-8 8.pdf

[12] G. McGovern, "Intranet Return on Investment Case Studies," 2002.

http://www.gerrymcgovern.com/nt/2002/nt_2002_11_18_ intranet_roi.htm

[13] H. Lebo, "The UCLA Internet Report-Surveying the Digital Future,” 2003.

http://images.forbes.com/fdc/mediaresourcecenter/UCLA 03.pdf

[14] A. C. Zorzi, "Electronic Commerce and Development Implications for IDB Action," 2000. http://idbdocs.iadb.org/wsdocs/getdocument.aspx?docnu $\mathrm{m}=1484412$ 